\title{
Predictive factors of death in patients with tuberculosis: a nested case-control study
}

M. Moosazadeh, ${ }^{7}$ A. Nezammahalleh, ${ }^{2}$ M. Movahednia, ${ }^{3}$ N. Movahednia, ${ }^{3}$ N. Khanjani ${ }^{4}$ and M. Afshari ${ }^{3}$

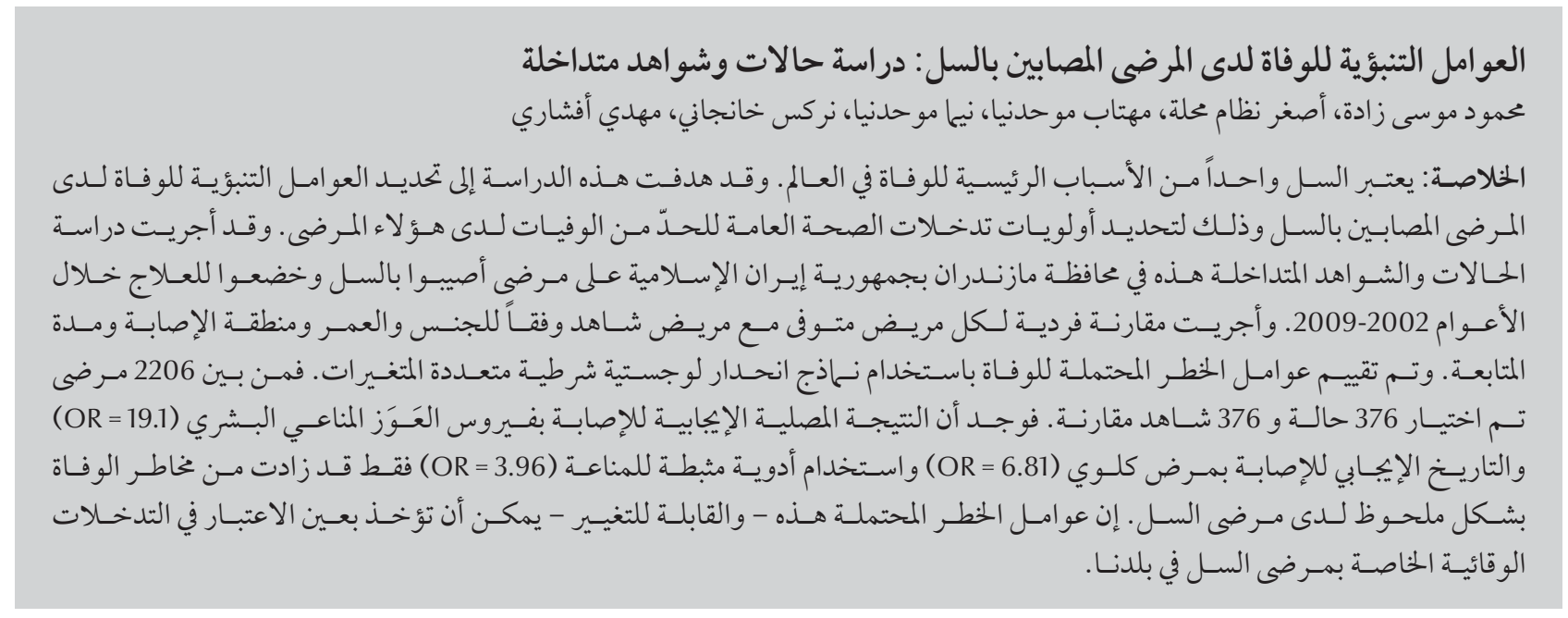

ABSTRACT Tuberculosis is one of the main causes of death worldwide. This study aimed to determine predictive factors for death in patients with tuberculosis to set priorities for public heath interventions to reduce mortality in these patients. This nested case-control study was carried out in Mazandaran province of Islamic Republic of Iran among tuberculosis patients who were treated during 2002-2009. Each deceased patient was individually matched with a control patient according to sex, age, area of involvement and time of follow-up. Potential risk factors for death were evaluated using multivariate conditional logistic regression models. From 2206 patients 376 cases and 376 matched controls were selected. Only positive serology for HIV (OR = 19.1), history of kidney disease $(O R=6.81)$ and use of immunosuppressant drugs $(O R=3.96)$ significantly increased the risk of death in tuberculosis patients. These potentially modifiable risk factors could be taken into account in preventive interventions for tuberculosis patients in our country.

Facteurs prédictifs de décès chez des patients atteints de tuberculose : étude cas-témoin nichée dans une cohorte

RÉSUMÉ La tuberculose est l'une des principales causes de décès dans le monde. La présente étude avait pour objectif de déterminer les facteurs prédictifs de décès chez des patients atteints de tuberculose afin de fixer des priorités pour les interventions de santé publique visant à réduire la mortalité chez ces patients. La présente étude cas-témoin nichée dans une cohorte a été menée dans la province de Mazandaran (République islamique d'Iran) auprès de patients tuberculeux ayant été traités entre 2002 et 2009. Chaque patient décédé a été individuellement apparié à un patient témoin pour le sexe, l'âge et le site de la lésion ainsi que la période de suivi. Des facteurs de risque potentiels de décès ont été évalués à l'aide de modèles de régression logistique conditionnelle multivariée. Sur un total de 2206 patients, 376 cas et 376 témoins appariés ont été sélectionnés. Seuls une sérologie positive pour le VIH $(O R=19,1)$, des antécédents d'insuffisance rénale $(O R=6,81)$ et le recours à des immunosuppresseurs $(O R=3,96)$ augmentaient significativement le risque de décès chez ces patients atteints de tuberculose. Ces facteurs de risque potentiellement modifiables pourraient être pris en compte dans des interventions préventives visant les patients atteints de tuberculose dans notre pays.

${ }^{1}$ Health Sciences Research Centre, School of Health; ${ }^{2}$ Office of Health Deputy, Mazandaran University of Medical Sciences, Sari, Islamic Republic of Iran. ${ }^{3}$ School of Health, Zabol University of Medical Sciences, Zabol, Islamic Republic of Iran (Correspondence to M. Afshari: mehdiafshari16@ yahoo.com). ${ }^{4}$ Neurology Research Centre, Shafa Hospital, Kerman University of Medical Sciences, Kerman, Islamic Republic of Iran.

Received: 14/09/14; accepted: 23/02/15 


\section{Introduction}

Tuberculosis is a major public health concern in the world (1). Nearly a third of the world's population is estimated to be infected with Mycobacterium tuberculosis. Tuberculosis is also the main cause of almost 2 million deaths per year (2), accounting for $25 \%$ of all preventable deaths especially in low-income countries among economically productive age groups $(3,4)$. About $60-70 \%$ of smear-positive tuberculosis patients would die if they were left untreated, while treatment under the DOTS (directly observed treatment short-course) strategy decreases the fatality rate to $5 \%$. These estimates are lower in smearnegative tuberculosis patients (5).

According to the Millennium Development Goals, United Nations' Member States are on track to achieve the Stop TB Partnership target of a 50\% declinein tuberculosis mortality by 2015 (6). To achieve this goal, it is important to design interventions to improve the outcomes of tuberculosis. Interventions such as diagnosis and treatment of patients, active case-finding, implementation of DOTS and preventive therapy have differing effects on mortality rates (5). Several studies have been carried out to determine factors associated with mortality among tuberculosis patients. According to these, the mortality rate increases with age, treatment duration (under 6 months) (7), smear-positive disease (8), male sex, late initiation of treatment, smoking, cases of mixed pulmonary and extrapulmonary forms, resistance to drugs, co-infection with HIV/AIDS, low family income (9) and alcohol abuse (4).

The Islamic Republic of Iran is an endemic country for tuberculosis. In 2012, the mortality rate of tuberculosis in patients with and without HIV infection was estimated to be 0.11 and 2.9 per 100000 population respectively (10). This study was conducted to estimate the factors associated with death in a cohort of tuberculosis patients who started tuberculosis treatment in the north of the country. The results of the study were expected to help identify opportunities for effective interventions with the potential to decrease mortality among tuberculosis patients.

\section{Methods}

\section{Study design and sampling}

This nested case-control study was carried out in Mazandaran, one of the northern provinces of Islamic Republic of Iran. Study subjects consisted of a cohort of patients who began treatment for tuberculosis during the period between 2002 and 2009. In 2013, we followed these cohorts retrospectively and when an individual with tuberculosis died (case), we selected another patient with similar characteristics who was alive at the time of the case's death (as a control).

All cases and controls were registered in the Iranian national tuberculosis control programme. Controls were individually matched with cases according to sex, age, area of involvement (pulmonary or extrapulmonary) and time of follow-up. We traced all patients whose treatment duration had finished at the time of study to detect their current status. For this purpose, all relevant information within rural and urban health centres as well as the provincial tuberculosis control centre were used.

\section{Data collection}

For each participant, data on the following variables were collected from data registries archived in centres for tuberculosis control and prevention in Mazandaran University of Medical Science: treatment regimen, nationality, history of being in prison, history of using immunosuppressive drugs, HIVpositive status, type of disease (new, transfer in, relapse or treatment after interruption), area of residence (rural or urban), history of complications, renal disease (serum creatinine level of $\geq 2 \mathrm{mg} / \mathrm{dL}$ ), chronic pulmonary disease, multi-drug resistance and substance abuse (e.g. opium, intravenous drugs).

Patients whose survival status was undetectable, those with unreliable diagnosis and also cases without a suitable matched control were excluded from the cohort. Only patients who agreed to participate were recruited to the study.

\section{Data analysis}

The frequency of categorical variables between cases and controls were compared using Fisher exact test. Potential risk factors for death were estimated using multivariate conditional logistic regression models. All variables significantly associated with the outcome (death) in the univariate model (treatment regimen, HIV status, renal disease, history of using immunosuppressive drugs and type of tuberculosis) were entered in the final model. $P$-values $<0.05$ were considered significant. All statistical analyses were performed using Stata, version 11 software.

\section{Results}

There were 2206 registered tuberculosis patients; 252 subjects were excluded due to unknown survival status and 47 patients were excluded because of misdiagnosis. From the remaining patients 376 cases and 376 matched controls were chosen. Of the patients, 147 patients died during treatment and the others died after successful treatment.

In the univariate model the frequency of type 2 treatment category ( 8 months) among cases was significantly higher than that of the controls $(7.2 \%$ versus $2.4 \%, P=0.002)$, as was the type of case (relapsed) (5.0\% versus $2.1 \%$, $P=0.04)$. History of kidney disorder $(6.1 \%$ versus $1.1 \%, P<0.001)$, use of immunosuppressive drugs $(7.2 \%$ versus $1.6 \%, P<0.001)$ and also HIV infection 


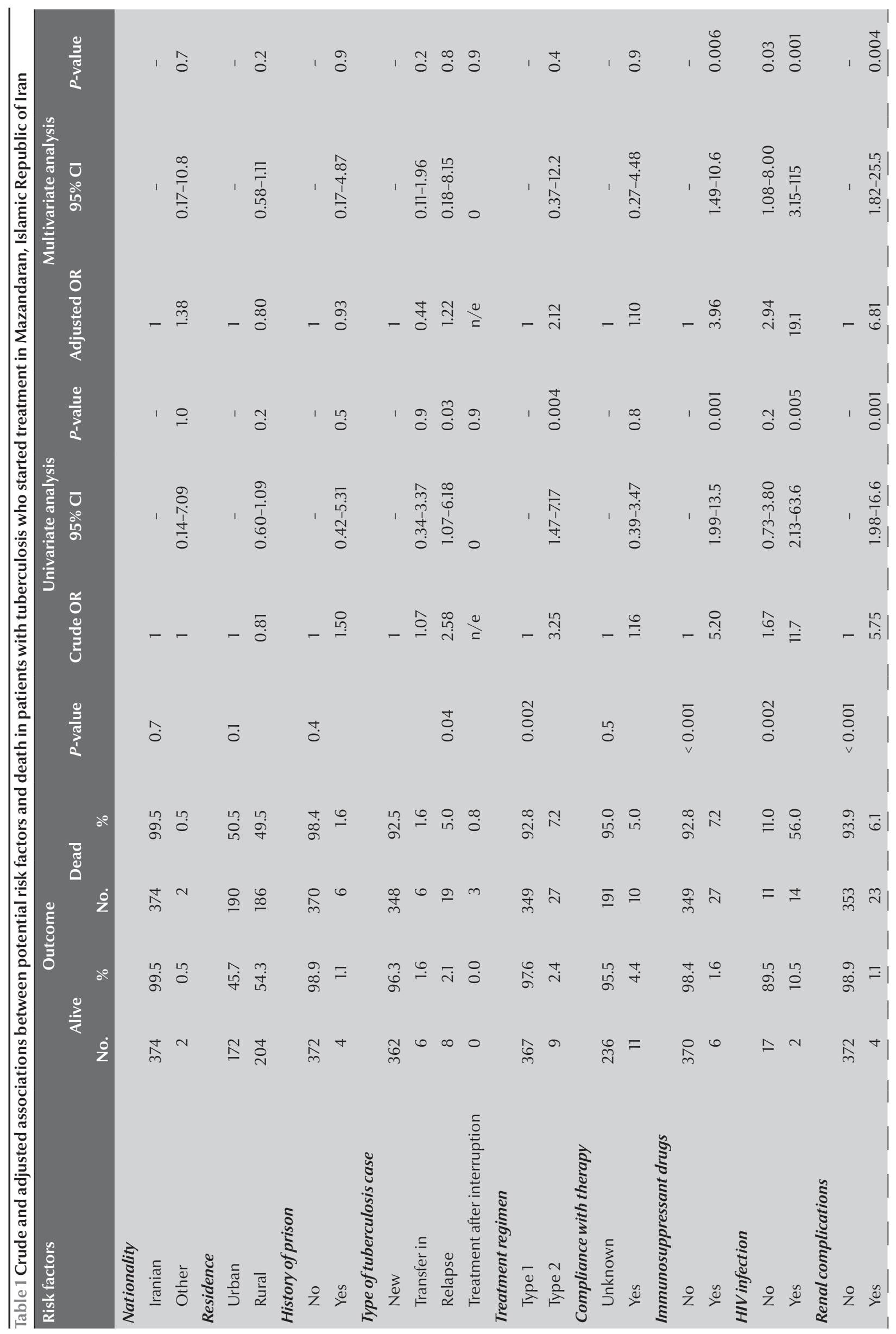




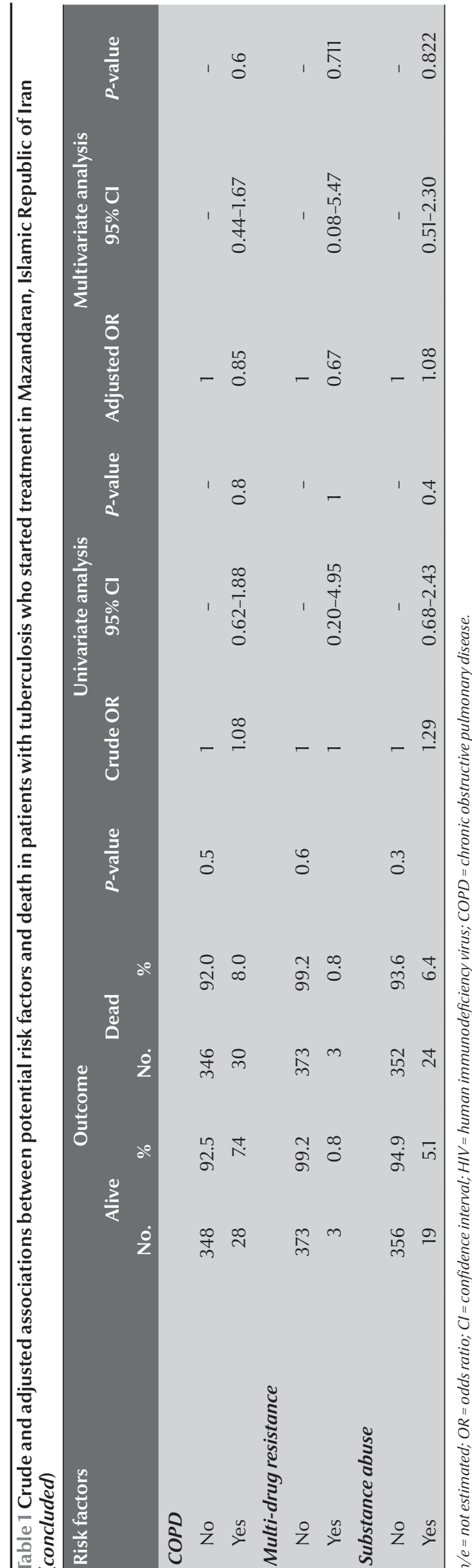

( $56 \%$ versus $10.5 \%, P=0.002$ ) were significantly higher in cases than in controls (Table 1). These variables were entered in the final regression model.

As illustrated in Table 1, after multivariate analysis, only HIV infection (adjusted OR $=19.1, P<0.001$ ), history of kidney disease ( $\mathrm{OR}=6.81, P=0.004)$ and use of immunosuppressant drugs $(\mathrm{OR}=3.96, \mathrm{P}=0.006)$ were found to significantly increase the risk of death in tuberculosis patients.

\section{Discussion}

In this study, in a multivariate regression model positive serology for HIV, history of renal disease and use of immunosuppressant drugs were associated with mortality in tuberculosis patients.

It has been shown that patients suffering from tuberculosis are at a higher risk of dying than the general population, especially during treatment (4). Because death during the course of treatment is not a comprehensive indicator of mortality in tuberculosis (9), we had to investigate the death several years after treatment of tuberculosis patients. It also has been argued that the final outcome of tuberculosis patients under treatment may not reflect the final survival state of these patients due to the production of chronic changes in the lungs leading to a reduction in their chance of survival (4).

We observed that positive serology for HIV increased the risk of death in patients with a history of tuberculosis by more than 12-fold. Similar to our findings, Millet et al. (4) and Girardi et al. (11) showed a mortality rate up to 10 times higher in HIVpositive patients compared to those without positive serology of HIV. Moreover, in studies conducted by Van den Broek et al. (12) and Albuquerque et al. (9), HIV positivity was reported as an important predictive factor of death from tuberculosis. Several factors, such as delays in diagnosis and treatment of HIV-positive patients whose sputum smear is usually negative, and also more advanced immunosuppression, can explain this poor outcome (7).

As expected, we observed that a history of kidney disease and immunosuppressant drug therapy were risk factors for death among tuberculosis patients. These factors increased the risk of death about 7 and 4 times respectively. Such mortality may be because of the background disorders and not due to the tuberculosis itself. Further studies are needed to examine the isolated effects of such factors.

In the final regression model we found no association between the type of tuberculosis case (new, transfer in, relapse, treatment after interruption) and death. These findings are in agreement with those found by Millet et al. (4) and Sterling et al. (13), who reported that tuberculosis recurrence and previous tuberculosis treatment were not associated with mortality. However, the results contrast with those of Sonnenberg et al., 
Somoskovi et al. $(14,15)$ and Girardi et al. (11), who found significant associations. Other studies have shown the role of non-compliance as a risk factor for mortality among tuberculosis patients $(16,17)$. These differences could be partially due to different definitions of recurrence and relapse. In addition, a lack of association between tuberculosis recurrence and death in the current study could be due to complete and correct treatment under the DOTS strategy of patients in their second phase of tuberculosis treatment.

As reported in Millet et al.'s study (4), no association between multi-drug resistance status and mortality was observed which concurs with our finding. Perhaps such patients in the study region had completed the tuberculosis treatment successfully. However, some other studies conducted in different parts of the world showed positive associations between multi-drug resistance and tuberculosis mortality $(18,19)$.

We investigated the effects of a number of other factors in our study in addition to the above-mentioned variables, such as area of residence, nationality, history of imprisonment, tuberculosis complications and substance abuse, but none of them were associated with death in patients with a history of tuberculosis. Although age and treatment duration has been shown in several studies to be associated with death from tuberculosis $(7,20,21)$, we controlled for these factors in our study by individual matching when selecting controls.

The diversity of methodologies used in different studies conducted to investigate predictors of death among tuberculosis patients make it difficult to comprehensively compare the risk factors found in these studies with ours. Another limitation of the current study is that we did not assess the characteristics of non-participants in the study for comparison with those of participants.

\section{Conclusion}

In conclusion, our study showed evidence that some modifiable risk factors-HIV co-infection, history of kidney disease and use of immunosuppressant drugs - were associated with mortality in Iranian patients with a history of tuberculosis. Therefore, effective prevention and treatment interventions should be implemented to increase the quality of life in these patients and to reduce mortality among them.

\section{Acknowledgements}

\section{Funding: None.}

Competing interests: None declared.

\section{References}

1. Haghdoost A, Afshari M, Baneshi MR, Gouya MM, Nasehi M, Movahednia M. Estimation of annual risk of tuberculosis infection and disease in southeast of Iran using Bayesian mixture method. Iran Red Crescent Med J. 2014;16(9):e15308.

2. Moosazadeh M, Khanjani N, Bahrampoor A. Seasonality and temporal variations of tuberculosis in the north of Iran. Tanaffos. 2013;12(4):35-41.

3. Moosazadeh M, Khanjani N, Bahrampour A, Nasehi M. Does tuberculosis have a seasonal pattern among migrant population entering Iran? Int J Health Policy Manag. 2014;2:181-5.

4. Millet JP, Orcau A, Rius C, Casals M, de Olalla PG, Moreno A, et al. Predictors of death among patients who completed tuberculosis treatment: a population-based cohort study. PLoS ONE. 2011;6(9):e25315.

5. Borgdorff MW, Floyd K, Broekmans JF. Interventions to reduce tuberculosis mortality and transmission in low-and middle-income countries. Bull World Health Organ. 2002;80(3):217-27.

6. Moosazadeh M, Khanjani N, Bahrampour A, Nasehi M, Sharafi S, Ahmadi S. Forecasting tuberculosis incidence in Iran using Box-Jenkins models. Iran Red Crescent Med J. 2014;16(5):e11779.

7. Nájera-Ortiz JC, Sánchez-Pérez HJ, Ochoa-Díaz-López H, Leal-Fernández G, Navarro-Giné A. The poor survival among pulmonary tuberculosis patients in Chiapas, Mexico: the case of Los Altos region. Tuberc Res Treat. 2012;2012(1-6):708-23. PMID: 22701170

8. Cavanaugh JS, Shah NS, Cain KP, Winston CA. Survival among patients with HIV infection and smear-negative pulmonary tuberculosis-United States, 1993-2006. PLoS ONE. 2012;7(10):e47855.

9. Albuquerque MFPM, Batista JAL, Ximenes RAA, Ximenes MS, Diniz GTN, Rodrigues LC. Risk factors associated with death in patients who initiate treatment for tuberculosis after two different follow-up periods. Rev Bras Epidemiol. 2009;12(4):513-22.

10. Global tuberculosis report 2012. Geneva: World Health Organization; 2012 (http://apps.who.int/iris/bitstre am/10665/137094/1/9789241564809_eng.pdf?ua=1, accessed 25 March 2015).

11. Girardi E, Antonucci G, Vanacore P, Palmieri F, Matteelli A, lemoli E, et al. Tuberculosis in HIV-infected persons in the context of wide availability of highly active antiretroviral therapy. Eur Respir J. 2004;24(1):11-7.

12. van den Broek J, Mfinanga S, Moshiro C, O'Brien R, Mugomela A, Lefi M. Impact of human immunodeficiency virus infection on the outcome of treatment and survival of tuberculosis patients in Mwanza, Tanzania. Int J Tuberc Lung Dis. 1998;2(7):547-52.

13. Sterling TR, Zhao Z, Khan A, Chaisson RE, Schluger N, Mangura $B$, et al. Mortality in a large tuberculosis treatment trial: modifiable and non-modifiable risk factors. Int J Tuberc Lung Dis. 2006;10(5):542-9.

14. Sonnenberg P, Murray J, Glynn JR, Shearer S, Kambashi B, Godfrey-Faussett P. HIV-1 and recurrence, relapse, and reinfection of tuberculosis after cure: a cohort study in South African mineworkers. Lancet. 2001;358(9294):1687-93.

15. Somoskovi A, Parsons LM, Salfinger M. The molecular basis of resistance to isoniazid, rifampin, and pyrazinamide in Mycobacterium tuberculosis. Respir Res. 2001;2(3):164-8.

16. Domingos MP1. Caiaffa WT, Colosimo EA. Mortality, TB/HIV co-infection, and treatment dropout: predictors of tuberculosis prognosis in Recife, Pernambuco State, Brazil. Cad Saude Publica. 2008;24(4):887-96. 
17. Kolappan C, Subramani R, Karunakaran K, Narayanan PR Mortality of tuberculosis patients in Chennai, India. Bull World Health Organ. 2006;84(7):555-60.

18. Wells CD, Cegielski JP, Nelson LJ, Laserson KF, Holtz TH, Finlay A, et al. HIV infection and multidrug-resistant tuberculosis: the perfect storm. J Infect Dis. 2007;196 Supplement 1:S86-107.

19. Lefebvre N, Falzon D. Risk factors for death among tuberculosis cases: analysis of European surveillance data. Eur Respir J. 2008;31(6):1256-60.
20. Low S, Ang LW, Cutter J, James L, Chee CB, Wang YT, et al. Mortality among tuberculosis patients on treatment in Singapore. Int J Tuberc Lung Dis. 2009;13(3):328-34.

21. Vree M, Huong NT, Duong BD, Sy DN, Van le N, Co NV, et al. Mortality and failure among tuberculosis patients who did not complete treatment in Vietnam: a cohort study. BMC Public Health. 2007;7(1):134. 